\title{
Intracolonic administration of zileuton, a selective 5-lipoxygenase inhibitor, accelerates healing in a rat model of chronic colitis
}

X Bertrán, J Mañé, F Fernández-Bañares, E Castellá, R Bartolí, I Ojanguren, M Esteve, M A Gassull

\begin{abstract}
Background-5-Lipoxygenase products play a part in inflammatory response. Aims-The effect of intracolonic administration of zileuton (a 5-lipoxygenase inhibitor) on colonic damage and eicosanoid local release was assessed in a rat model of colitis.

Methods-Ninety rats with trinitrobenzenesulphonic acid induced colitis were randomised to receive placebo, 5-aminosalicylic acid $(50 \mathrm{mg} / \mathrm{kg})$, or zileuton (50 $\mathrm{mg} / \mathrm{kg}$ ) intracolonically for four weeks. Local eicosanoid release was monitored by intracolonic dialysis throughout the study. The colon was removed for macroscopic and histological assessment at weeks 1,2 , and 4 after colitis induction in 10 rats of each group.

Results-Zileuton significantly reduced macroscopic damage score after four weeks of treatment in comparison with the other two groups $(p=0.034)$. In addition, zileuton administration significantly increased the intracolonic release of both thromboxane $B_{2}$ at week $1(p=0.05)$ and prostaglandin $E_{2}$ at weeks 2 and 4 $(\mathbf{p}<0 \cdot 05)$. Zileuton and 5-aminosalicylic acid decreased leukotriene $B_{4}$ release by $90 \%$ at day 3.
\end{abstract}

Conclusions-Intracolonic zileuton, compared with 5-aminosalicylic acid and placebo,seems to improve the course of the disease in a model of chronic colitis. This effect may be related to an increased and maintained production of prostaglandin $E_{2}$ together with inhibition of leukotriene $B_{\mathbf{4}}$ synthesis.

(Gut 1996; 38: 899-904)

Department of Gastroenterology X Bertrán J Mañé

F Fernández-Bañares

R Bartolí

$M$ Esteve

M A Gassull

and Pathology

E Castellá

I Ojanguren

Research Unit, Hospital Universitari Germans Trias i Pujol, Badalona, Spain

Correspondence to: Dr M A Gassull, Hospital Universitari Germans Trias Pujol, Carretera del Canyet $\mathrm{s} / \mathrm{n}, 08916$ Badalona, Spain.

Accepted for publication 21 December 1995
Keywords: experimental colitis,

trinitrobenzenesulphonic acid, zileuton, 5-ASA eicosanoids, 5-lipoxygenase.

The aetiology of inflammatory bowel disease (IBD) remains undefined, but it is recognised that in both acute and chronic forms, inflammatory mediators are generated within the colonic mucosa. Some of these mediators, the eicosanoids (thromboxanes, prostaglandins, and leukotrienes) are products of the metabolism of arachidonic acid by the action of both cyclooxygenase and 5-lipoxygenase. ${ }^{1}$

The role for lipoxygenase products of arachidonic acid in the pathogenesis of IBD is supported by the finding in experimental models of colitis that the concentration of leukotrienes (mainly leukotriene $\mathrm{B}_{4}\left(\mathrm{LTB}_{4}\right)$ ) in the inflamed mucosa is within the range known to induce biological effects (chemokinesis, cell aggregation, increasing of vascular permeability), and these concentrations are similar to those seen in human IBD. ${ }^{2-7}$ In addition, drugs known to be effective in the treatment of IBD are capable of reducing intestinal leukotriene production in both experimental models of colitis and human IBD. ${ }^{3-6}$ On the other hand, administration of potent and selective inhibitors of leukotriene synthesis results in a reduction of macroscopic and histological colonic damage in experimental colitis. ${ }^{6-11}$

Zileuton, $N$-(1-(benzo[b] thien-2-yl)ethyl)$N$-hydroxyurea (Abbott Laboratories, Abbott Park, IL), is a drug that selectively inhibits the activity of 5-lipoxygenase. In humans, the oral administration of a single dose of $800 \mathrm{mg}$ reduces the synthesis of $\mathrm{LTB}_{4}$ measured in rectal dialysates by approximately $67 \%$ within four hours, with no significant toxicity. ${ }^{12}$ In recent double blind randomised trials, however, the use of zileuton at doses ranging from $800 \mathrm{mg}$ twice daily to $600 \mathrm{mg}$ four times a day, either as treatment of active disease or for maintenance of remission, in patients with ulcerative colitis, have shown poor or marginal results. ${ }^{1314}$ For this reason, the evaluation of alternative routes of administration of zileuton, such as intrarectal, may be of importance to assess the possibility of improving the therapeutic effect of this drug.

The aim of this study was to assess the effect of the intracolonic administration of zileuton, compared with 5-aminosalicylic acid (5-ASA) and placebo, on the macroscopic and histological damage and on the eicosanoid local release in an experimental model of colitis in rats.

\section{Methods}

\section{Animals}

Female virgin Sprague-Dawley rats weighing 200-250 $\mathrm{g}$ were used in this study. The animals were maintained in a restricted access room with controlled temperature $\left(23^{\circ} \mathrm{C}\right)$ and light/dark cycle $(16 \mathrm{~h}: 8 \mathrm{~h})$. The rats were housed in individual isolated rack mounted wire cages. Standard laboratory pelleted formula (Rat chow, Panlab, Barcelona, Spain) and tap water were provided ad libitum. The study was conducted, in agreement with the guidelines for animal research, according to 
the Guide for the Care and Use of Laboratory Animals, and was approved by the research and ethical committee of our hospital.

\section{Experimental colitis}

Experimental colitis was induced using the method described by Morris et al. ${ }^{15}$ In brief, rats were lightly anaesthetised with ether and a polyurethane catheter (OD $2 \mathrm{~mm}$ ) was inserted rectally into the colon so that the tip was $8 \mathrm{~cm}$ proximal to the anus, approximately at the splenic flexure. Then, $0.25 \mathrm{ml}$ of a mixture of $30 \mathrm{mg}$ of trinitrobenzenesulphonic acid (TNB) (Sigma-Aldrich Química, Madrid, Spain) dissolved in $50 \%$ ethanol (vol/vol) was instilled into the lumen of the colon. The instillation procedure required five seconds to complete. Finally, $0.5 \mathrm{ml}$ of air was injected to clear completely the TNB/ethanol solution from the cannula, and the anaesthetised animals were kept for a few minutes in a supine Trendelenburg position.

\section{Experimental design}

TNB/ethanol colitis was induced in 90 rats. Animals were thereafter randomised into three therapeutic groups to receive daily, from day 1 (24 hours after induction of colitis):

Group $A(n=30)-0.25 \mathrm{ml}$ of vehicle solution enema ( $1.5 \%$ carboxymethylcellulose in saline serum) (placebo group).

Group B $(n=30)-0.25 \mathrm{ml}$ of the vehicle solution enema added with $50 \mathrm{mg} / \mathrm{kg}$ of body weight of 5-ASA.

Group $C(n=30)-0.25 \mathrm{ml}$ of the vehicle solution enema added with $50 \mathrm{mg} / \mathrm{kg}$ of body weight of zileuton.

In addition, a sham colitis was induced, by intrarectal administration (as described above) of $0.25 \mathrm{ml}$ of $0.9 \%$ saline, in 10 rats (control group).

At day 1 and 3, and at weeks 1, 2, and 4, 10 rats from groups $\mathrm{A}, \mathrm{B}$, and $\mathrm{C}$ were randomly selected for the assessment of eicosanoid release in the lumen of the colon by intracolonic dialysis. Rats were anaesthetised with $100 \mathrm{mg}$ of intraperitoneal thiopental and intracolonic dialysis was performed using hydrated Visking seamless cellulose tubing (8/32, 6.3 $\mathrm{mm}$ diameter, $7 \mathrm{~cm}$ long; Medicell International, London) attached by a $10 \mathrm{~cm}$ polyurethane cannula to an external syringe. After inserting the entire cannula into the distal colon, the dialysis bag was filled with $1 \mathrm{ml}$ of dialysis solution, consisting of $0.3 \%$ bovine serum albumin in a solution of $120 \mathrm{mmol} / 1$ $\mathrm{NaCl}$ and $30 \mathrm{mmol} / \mathrm{K} \mathrm{KHCO}_{3}$ adjusted to $\mathrm{pH}$ $7 \cdot 90$. One hour later, ${ }^{5}$ the fluid was withdrawn and immediately stored at $-30^{\circ} \mathrm{C}$. The volume of the dialysate recovered at the end of the one hour period was higher than $90 \%$. In the control group $(n=10)$, an intracolonic dialysis was performed in the same way 24 hours after the sham colitis induction.

The day after the dialysis was performed at weeks 1,2 , and 4 , the same animals were given a distal colectomy under total anaesthesia with $100 \mathrm{mg}$ of intraperitoneal thiopental, to assess
TABLE I Macroscopic damage score

\begin{tabular}{lr}
\hline Adhesions & 0 \\
None & 1 \\
Minimal & 2 \\
Involving several bowel loops & 0 \\
Strictures & 2 \\
None & 3 \\
Mild & 0 \\
Severe; proximal dilatation & 1 \\
Ulcers & 2 \\
None & 3 \\
Linear ulceration $<1 \mathrm{~cm}$ & 0 \\
Two linear ulcers $<1 \mathrm{~cm}$ & 1 \\
More sites of ulceration or one large ulcer $>1 \mathrm{~cm}$ & 2 \\
Wall thickness & 10 \\
Less than $1 \mathrm{~mm}$ & \\
$1-3 \mathrm{~mm}$ & \\
More than $3 \mathrm{~mm}$ & \\
$\quad$ Maximum score & \\
\hline
\end{tabular}

colonic inflammation macroscopically and histologically. The excised colon was opened longitudinally, rinsed with normal saline, pinned out on a wax block, and assigned a code number. Mucosal damage was assessed macroscopically as described later. Afterwards, three tissue specimens $(2 \times 10 \mathrm{~mm})$ were obtained from the colon. When no severely visible inflammation was present, the specimens were taken from the regions $1 \mathrm{~cm}, 3 \mathrm{~cm}$, and $8 \mathrm{~cm}$ proximal to the anus. When visible lesions were present, the specimens were taken from the affected regions. Tissue samples were fixed in formaldehyde and routinely processed. In the control group $(n=10)$ the rats were killed in the same way 48 hours after induction of sham colitis.

\section{Assessment of colonic inflammation}

The macroscopic assessment of colonic damage was immediately made using a stereomicroscope by two observers blinded to the treatment. Each colon was assigned a score on a scale ranging from 0 to 10 based on the presence of adhesions, strictures, ulcers, and wall thickness (Table I). ${ }^{16}$

The samples taken to study the histological damage were embedded in paraffin wax. Sections $(7 \mu)$ were stained with haematoxylin and eosin. The histological damage was scored on a scale ranging from 0 to 10 based on the presence of ulceration, inflammation, granu-

TABLE II Histological damage score

\begin{tabular}{lr}
\hline Ulceration & \\
No ulcer; epithelisation & 0 \\
Small ulcers $<3 \mathrm{~mm}$ & 1 \\
Large ulcers $>3 \mathrm{~mm}$ & 2 \\
Inflammation & 0 \\
None & 1 \\
Mild & 2 \\
Severe & \\
Granuloma & 0 \\
None & 1 \\
Presence & \\
Depth of the lesion & 0 \\
None & 1 \\
Submucosa & 2 \\
Muscularis propria & 3 \\
Serosa & \\
Fibrosis & 1 \\
None & 2 \\
Mild & 10 \\
&
\end{tabular}

${ }^{\star}$ Epithelioid granuloma is defined using the criteria of Surawicz and Belic ${ }^{41}$ : collections of at least five epithelioid cells, with or without accompanying giant cells, and without caseation necrosis or foreign bodies. 
TABLE III Individual items and total score of macroscopic damage at first, second, and fourth weeks after administration of TNB (30 mg/50\%) in the three treatment groups. Each figure represents the mean (SEM) of at least seven rats

\begin{tabular}{|c|c|c|c|c|c|c|c|c|c|}
\hline \multirow[b]{2}{*}{ Weeks } & \multicolumn{3}{|l|}{ Placebo } & \multicolumn{3}{|l|}{ Zileuton } & \multicolumn{3}{|l|}{ 5- $A S A$} \\
\hline & 1 & 2 & 4 & 1 & 2 & 4 & 1 & 2 & 4 \\
\hline $\begin{array}{l}\text { Adhesions } \\
\text { Strictures } \\
\text { Ulcers } \\
\text { Wall thickness }\end{array}$ & $\begin{array}{l}1.5(0.2) \\
2.3(0.3) \\
2.7(0.1) \\
1.5(0.2)\end{array}$ & $\begin{array}{l}1.6(0.2) \\
2.6(0.2) \\
2.9(0 \cdot 1) \\
1.4(0.2)\end{array}$ & $\begin{array}{l}1.7(0.2) \\
1.4(0.4) \\
2 \cdot 1(0.3) \\
0.8(0.1)\end{array}$ & $\begin{array}{l}1.3(0.1) \\
2.6(0.2) \\
3.0(0.0) \\
1.2(0.1)\end{array}$ & $\begin{array}{l}1.6(0.2) \\
2.3(0.4) \\
2.3(0.5) \\
1.6(0.2)\end{array}$ & $\begin{array}{l}1.1(0.3) \\
0.6(0.4)^{\star} \\
1.4(0.3) \\
0.8(0.1)\end{array}$ & $\begin{array}{l}1.3(0.2) \\
2.6(0.2) \\
2.8(0.1) \\
1.8(0.1)\end{array}$ & $\begin{array}{l}1 \cdot 7(0 \cdot 2) \\
2 \cdot 3(0 \cdot 3) \\
2 \cdot 8(0 \cdot 1) \\
1 \cdot 3(0 \cdot 2)\end{array}$ & $\begin{array}{l}1.4(0.2) \\
1.9(0.3) \\
2.4(0.3) \\
1.2(0.2)\end{array}$ \\
\hline Total score & $8.0(0.5)$ & $8.5(0.3)$ & $6 \cdot 1(0 \cdot 8)$ & $8 \cdot 1(0.3)$ & $7.7(0.9)$ & $3.8(0.8) \dagger$ & $8.4(0.3)$ & $8 \cdot 1(0 \cdot 4)$ & $6.9(0.8)$ \\
\hline
\end{tabular}

${ }^{\star} \mathrm{p}=0.05$ and $\mathrm{tp}=0.034$ versus 5 -ASA and placebo at fourth week after TNB exposure.

loma, fibrosis and the depth of the lesion (Table II). ${ }^{16}$ Histological assessment by light microscopy was performed in a blinded fashion on coded slides.

\section{Eicosanoid radioimmunoassay}

Eicosanoid concentrations in the dialysates were measured by specific radioimmunoassays for prostaglandin $\mathrm{E}_{2}\left(\mathrm{PGE}_{2}\right)$, thromboxane $\mathrm{B}_{2}$ $\left(\mathrm{TXB}_{2}\right)$, and $\mathrm{LTB}_{4}$. The measurements were made two weeks after sample collection, in the laboratory of neurochemistry of the Centro Superior de Investigaciones Científicas (CSIC, Barcelona, Spain).

Immediately after intracolonic dialysis was performed, the dialysate samples obtained were acidified at $\mathrm{pH} 3.15$ and directly processed through Sep-Pak $\mathrm{C}_{18}$ cartridges (Water Chromatography Division, Millipore Co, Milford, MA). After washing with $10 \mathrm{ml}$ of acid water $(\mathrm{pH} 3 \cdot 15)$ and $10 \mathrm{ml}$ of petroleum ether, eicosanoids were finally eluted with $5 \mathrm{ml}$ of methyl formate and collected in propylene tubes. Afterwards, samples were evaporated of organic eluates to dryness, and stored at $-80^{\circ} \mathrm{C}$ until assay. The extraction efficiency of the three eicosanoids, tested with tritiated standards (Amersham International, UK), was similar (over 90\%) and highly reproducible (intra-assay variation of 2-5\%). ${ }^{17-19}$

All radioimmunoassay determinations were carried out in duplicate using specific antisera, being the detection sensitivity of $30-40 \mathrm{pg} / \mathrm{ml}$. Samples were resuspended in radioimmunoassay buffer and subjected to radioimmunoassay quantification. The recoveries were determined by scintillation counting. ${ }^{19}$ Antiserum for $\mathrm{PGE}_{2}$ was obtained from ERIA Diagnostics Pasteur (Marnes La Coquette, France). For $\mathrm{TXB}_{2}$ and $\mathrm{LTB}_{4}$ determination, non-commercial rabbit antisera were used. Cross reactivity of $\mathrm{PGE}_{3}$ with the $\mathrm{PGE}_{2}$ antiserum was $<0.01 \%$; $\mathrm{LTB}_{5}$ crossreacted with the $\mathrm{LTB}_{4}$ antiserum at $17 \cdot 1 \%$. The $\mathrm{PGE}_{2}$ and $\mathrm{TXB}_{2}$ antisera showed a cross reactivity for $\mathrm{TXB}_{2}$ and $\mathrm{PGE}_{2}$ of less than 0.01 and $0 \cdot 1 \%$, respectively. Validation of radioimmunoassay results were carried out using both the test of inhibition with anti-inflammatory drugs and the test of parallelism, ${ }^{20}$ obtaining in both cases strong correlations $(r=0.901$ and $r=0.953$, respectively).

\section{Statistical methods}

Results are expressed as mean (SEM). Significant differences between groups were evaluated using one-way analysis of variance. Duncan multiple range test was used to assess where the differences occur. Kruskall-Wallis one way analysis of variance by ranks and Mann-Whitney U test were used for non-parametric variables. Statistical analysis was performed using SPSS (SPSS Inc, Chicago, IL).

\section{Results}

\section{Effects of treatment on macroscopic colonic} damage

As previously described, intracolonic administration of TNB/ethanol resulted in extensive ulceration and transmural inflammation of the distal colon with severe thickening of the bowel wall and strictures. In addition, segmental pericolonic accumulations of mesenteric fat and fibrinous adhesions to the small bowel were frequently seen.

The macroscopic damage score evaluated at weeks 1 and 2 after the colonic injury was similar in the three groups studied. Zileuton treated rats, however, showed a significant reduction in the macroscopic damage score after four weeks of treatment compared with 5-ASA and placebo groups $(3.85(0.7) v 6.9$ $(0.8)$, and $6 \cdot 1(0.8)$, respectively; $p=0.034)$. All parameters measured by the score improved in zileuton group at four weeks compared with 5-ASA and placebo, mainly the development of strictures $(0.6(0.4) v 1.9(0.3)$ and $1.4(0.4)$, respectively; $\mathrm{p}=0.05$ ) (Table III).

In the control group, no macroscopic damage was observed 48 hours after the induction of the sham colitis.

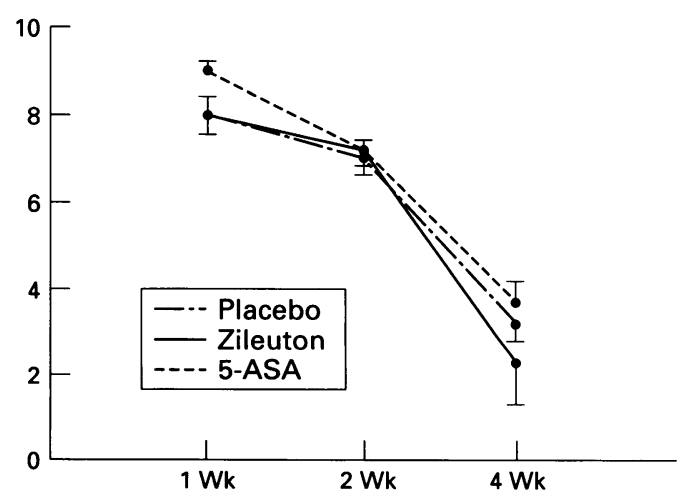

Figure 1: Effects of intracolonic administration of zileuton (50 mg/kg), 5-ASA (50 mg/kg) and placebo (vehicle) from days 1 to 28 on histological score after TNB induction of colitis ( $30 \mathrm{mg} / 50 \%)$. Each point represents the mean (SEM) of at least seven rats. There were no differences among the three groups studied. 

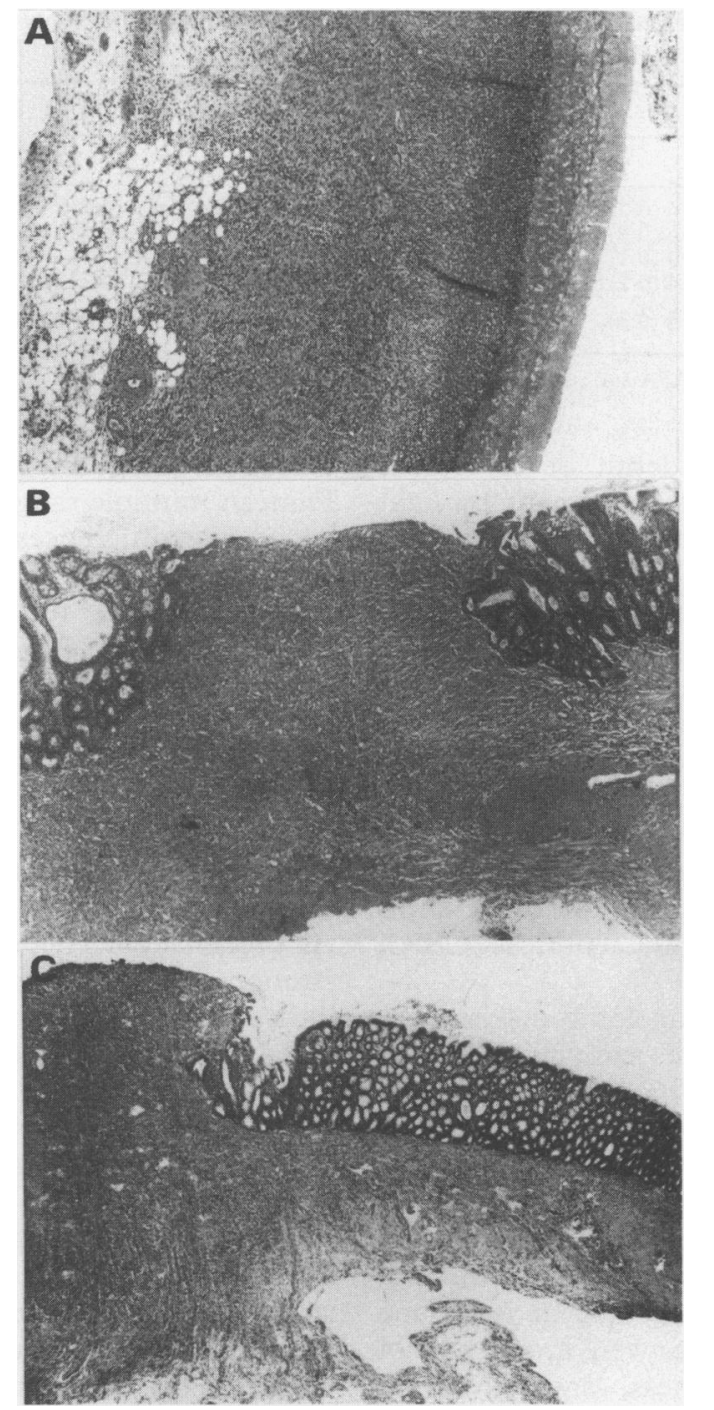

Figure 2: Rat colons at one, two, and four weeks after exposure to TNB (30 mg/50\%) (haematoxylin and eosin, magnification $\times 140$ ). (A) At first week, extensive ulcers with necrosis of mucosa and submucosa and infiltration with polymorphonuclear leucocytes were observed. (B) At second week, necrotic areas of mucosa and submucosa were replaced by exuberant granulation tissue. Mucosa adjacent to ulcers showed important glandular distortion, globet cells depletion, and cystically dilated cripts. (C) Four weeks after TNB administration, ulcers were partially reepithelisated. A mild chronic inflammatory infiltrate was evident in either mucosa and submucosa. Fibrosis extended through the whole

thickness of the bowel wall from superficial mucosa to serosa.

Effects of treatment on histological score

There were no differences in the histological score among the groups, at weeks 1,2 and 4 (Fig 1). The characteristics of the lesions observed were similar to those previously described $^{51115}$ (Fig 2).

\section{Effect of treatment on intracolonic eicosanoid release}

As shown in Figures 3, 4, and 5, TNB induction of colitis resilted in a significant increase in intracolonic $\mathrm{TXB}_{2}, \mathrm{PGE}_{2}$, and $\mathrm{LTB}_{4}$ release when compared with the sham colitis group. These increased concentrations were maintained throughout the study period.

Administration of zileuton produced a significant increase in the intracolonic release of both $\mathrm{TXB}_{2}(\mathrm{p}=0.05$ at week 1 compared with either placebo or 5-ASA) and $\mathrm{PGE}_{2}$

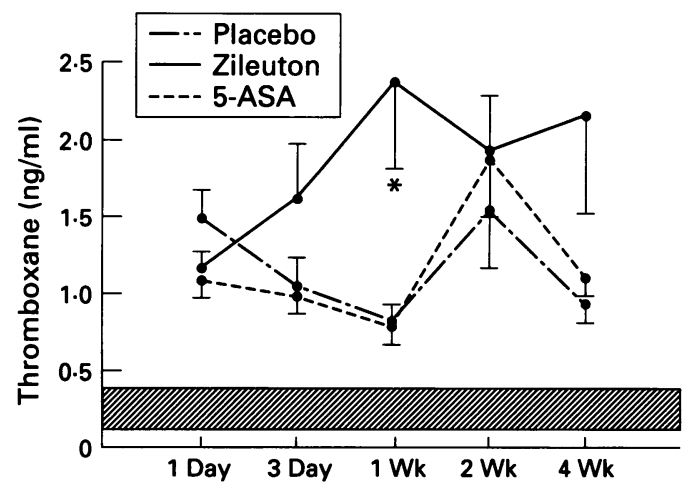

Figure 3: Influence of intracolonic administration of zileuton $(50 \mathrm{mg} / \mathrm{kg}), 5-A S A(50 \mathrm{mg} / \mathrm{kg})$, and placebo (vehicle) from days 1 to 28 after TNB administration ( $30 \mathrm{mg} / 50 \%$ ) on luminal $T X B_{2}$ release. Each point represents the mean (SEM) of at least seven rats. Shaded area represents the $95 \%$ confidence interval of the mean value obtained from rats with sham colitis (intracolonic administration of $0.9 \%$ saline instead of TNB). At each time, $T X B_{2}$ levels in rats with TNB colitis and sham colitis differed significantly $(p<0.05)$. ${ }^{\star} p=0.05$ as compared with placebo and 5-ASA.

( $p=0.005$ at week 2 compared with either placebo or 5-ASA, and p $=0.04$ at week 4 compared with placebo) (Figs 3 and 4). $\mathrm{TXB}_{2}$ and $\mathrm{PGE}_{2}$ release did not differ between placebo and 5-ASA groups. On the other hand, both zileuton and 5-ASA administration resulted in a $90 \%$ abolition of $\mathrm{LTB}_{4}$ release at day 3 after induction of colitis compared with placebo (Fig 5).

Effect of treatment on dietary intake, weight changes, and mortality

There were no differences between the three therapeutic groups with regard to dietary intake and weight change during the study period. However, dietary intake was lower in the treatment groups than in healthy rats under the same living conditions and this was accompanied by weight loss of $12-15 \%$ during the first two weeks. Afterwards the growth rates returned to normal. Mortality was $20 \%$ in the three therapeutic groups: most deaths occurred in the first two weeks. Causes of death, assessed by laparotomy post mortem,

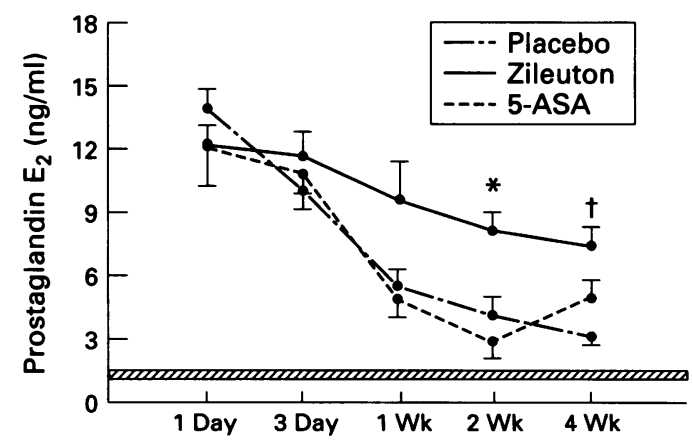

Figure 4: Influence of intracolonic administration of zileuton (50 mg/kg), 5-ASA (50 mg/kg), and placebo (vehicle) from days 1 to 28 after TNB administration ( $30 \mathrm{mg} / 50 \%$ ) on luminal $P G E_{2}$ release. Each point represents the mean (SEM) of at least seven rats. Shaded area represents the $95 \%$ confidence interval of the mean value obtained from rats with sham colitis (intracolonic administration of $0.9 \%$ saline instead of TNB). At each time, $P G E_{2}$ levels in rats with TNB colitis and sham colitis differed significantly $(p<0.05)$. ${ }^{\star} p=0.005$ versus both placebo and 5-ASA groups; $+p=0.04$ versus placebo. 


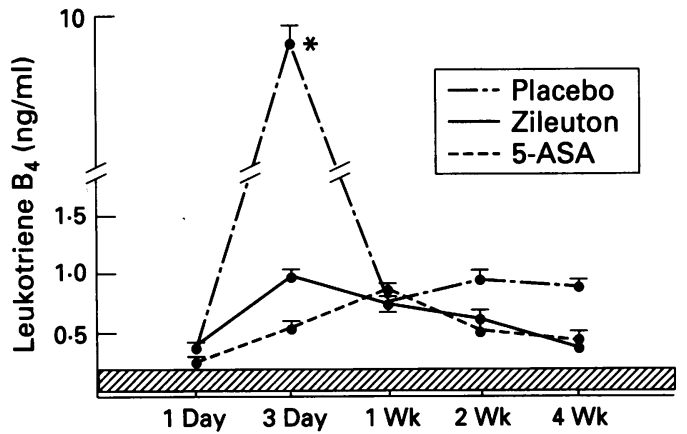

Figure 5: Influence of intracolonic administration of zileuton (50 mg/kg), $5-A S A(50 \mathrm{mg} / \mathrm{kg})$, and placebo (vehicle) from days 1 to 28 after TNB administration (30 mg/50\%) on luminal $\mathrm{LTB}_{4}$ release. Each point represents the mean (SEM) of at least seven rats. The shaded area represents the $95 \%$ confidence interval of the mean value obtained from rats with sham colitis (intracolonic administration of $0.9 \%$ saline instead of $T N B)$. At each time, $L T B_{4}$ levels in rats with TNB colitis and sham colitis differed significantly $(p<0.05) .{ }^{\star} p<0.005$ versus zileuton and 5-ASA.

were colonic occlusion (13 rats) and intestinal perforation (5 rats).

\section{Discussion}

TNB colitis in the rat is the animal model of IBD most extensively used over the past few years. The patterns of cytokine and mediator expression in this model parallel those seen in human IBD. ${ }^{21}$ Therefore, although the mechanisms by which inflammation is induced may be not ideal for studying the initial events of human IBD, it does provide a good model for gut injury, inflammation, and repair.

The evidence of an aetiopathogenic role of leukotrienes in the inflammatory process of experimental and human colitis has prompted several studies using different leukotriene synthesis inhibitors. ${ }^{6-112223}$ These substances resulted in a 50 to $90 \%$ inhibition of $\mathrm{LTB}_{4}$ synthesis. However, the administration of these drugs when colitis has already been induced did not improve the inflammatory process. $^{91023}$ Conversely, the administration of the drug before the induction of colitis (one to three hours beforehand) was associated with a reduction in the severity of the colonic inflammation. ${ }^{6-11}$

In the present study, the intracolonic administration of $50 \mathrm{mg} / \mathrm{kg}$ of zileuton after colitis induction decreased the local peak release of $\mathrm{LTB}_{4}$ by $90 \%$. As in previous studies using other 5-lipoxygenase inhibitors, this was not associated with an improvement in colonic inflammation parameters during the first two weeks. However, there was a significant reduction in the macroscopic colonic damage score at four weeks (chronic phase of colitis), when compared with placebo and 5-ASA, a finding not previously documented as most studies lasted only two weeks.

Although zileuton diminished the damage as measured by the macroscopic score, we did not observe any difference in the histological score between the three groups during the study period. This is probably because these scores evaluate different aspects. Macroscopic score measures the extension of the lesions both longitudinally and in depth, whereas the microscopic score evaluates inflammation in specimens that are always taken from inflamed areas independently of the extension and depth of the inflammatory process.

Although 5-ASA administration in our study promoted a potent inhibition of $\mathrm{LTB}_{4}$ peak release similar to that observed after zileuton, it did not ameliorate either the acute or chronic colonic damage when compared with placebo. This finding contrasts with previous reports. Vilaseca et $a l^{5}$ demonstrated a significant reduction in macroscopic and histological lesions after 21 days of treatment with intracolonic 5-ASA. However, the dose used in that trial was nearly 15-fold higher than in our study, and at least 10-fold higher than the dose used in treating human IBD. On the other hand, it has been shown that pretreating rats with colonically administered 5-ASA resulted in significantly less inflammation, ${ }^{69}$ whereas giving this treatment one day after TNB did not. ${ }^{9}$

In addition to the inhibition of $\mathrm{LTB}_{4}$ synthesis after treatment, monitoring of eicosanoid release allowed us to observe a maintained increase in post-treatment $\mathrm{PGE}_{2}$ production over the whole period of study. This was not observed after either placebo or 5-ASA treatment. Although less noticeable, there was also a maintained increase in $\mathrm{TXB}_{2}$ release after zileuton. These observations suggest that the inhibition of 5-lipoxygenase leads to a shifting of arachidonic acid to the cyclooxygenase pathway. In the only previous study on the effect of a 5-lipoxygenase inhibitor in TNB induced colitis, in which eicosanoid production was monitored over four weeks, a significant increase in prostaglandin synthesis was not observed. 6 Nevertheless, in that study 6-keto $\mathrm{PGF}_{1 \alpha}$ instead of $\mathrm{PGE}_{2}$ was measured as an index of cyclooxygenase activity. It is known that eicosanoid production is tissue and cell specific. The major source of $\mathrm{PGI}_{2}$ (precursor of 6-keto $\mathrm{PGF}_{1 \alpha}$ ) is the endothelial cell, whereas $P E_{2}$ may be produced by many cell types, even by epithelial cells.

For many years $\mathrm{PGE}_{2}$ was considered an important mediator of the inflammatory response in IBD. ${ }^{24-28}$ However, there is now clear evidence refuting this view. In fact inhibition of $\mathrm{PGE}_{2}$ by non-steroidal anti-inflammatory drugs exacerbated rather than improved the severity of experimental colitis, ${ }^{11}$ and in patients with IBD, the use of these drugs was associated with disease relapse. ${ }^{29} 30$ Moreover, exogenous prostaglandins have been shown to reduce the severity of intestinal damage in a number of experimental models of colitis. ${ }^{6} 31-33$ These observations suggest that prostaglandins are not proinflammatory and that they even promote healing through a variety of actions. In relation to this, a protective effect of these agents on the proliferative zone of the mucosa, ${ }^{33}$ and an association between $\mathrm{PGE}_{2}$ synthesis and the adherent surface colonic mucus secretion ${ }^{34}$ have been reported. On the other hand, $\mathrm{PGE}_{2}$ may exert many immunomodulatory changes in neutrophils, ${ }^{35} \mathrm{~T}$ lymphocytes, ${ }^{36}$ natural killer cells, ${ }^{37}$ and macrophages. ${ }^{38}$ Recent data also suggest that prostaglandins are involved in the 
formation of extracelluar matrix components and may decrease collagen synthesis after inflammation. 39 40

All these findings raise the possibility that maintaining increased levels of $\mathrm{PGE}_{2}$ over at least four weeks could be the main explanation for the different disease outcomes after zileuton and 5-ASA treatment, since the inhibition of $\mathrm{LTB}_{4}$ synthesis was similar in both actively treated groups of rats.

Thromboxanes have also been implicated in the pathogenesis of experimental colitis. The administration of two specific thromboxane inhibitors significantly reduced the severity of the chronic inflammatory lesions. The authors suggested that this effect was due to increased mucosal prostaglandin synthesis. ${ }^{5}$ The results of our study support this suggestion, since improvement in the intestinal damage was observed after zileuton treatment despite increased $\mathrm{TXB}_{2}$ synthesis.

In summary, this study suggests that chronic intracolonic administration of zileuton, a selective 5-lipoxygenase inhibitor, may improve the course of the disease, when compared with 5ASA and placebo. This effect may be related to an increased and maintained production of $\mathrm{PGE}_{2}$, together with the inhibition of the synthesis of $\mathrm{LTB}_{4}$.

The authors thank Dr Oriol Bulbena and Dr Gloria Gómez from CSIC for their help in performing eicosanoid radioimmunoassayss; Dr Pilar Giner from Pharmacy Service for skilful technical assistance in preparing enemata solutions. Zileuton was kindly supplied by Abbott Laboratories (Chicago, IL, USA).

1 Donowitz M Arachidonic acid metabolites and their role in inflammatory bowel disease. An update requiring addition of a pathway. Gastroenterology 1985; 88: 580-7.

2 Sharon P, Stenson WF Enhanced synthesis of leukotriene B by colonic mucosa in inflammatory bowel disease. Gastroenterology 1984; 86: 453-60.

3 Lauritsen K, Laursen LS, Bukhave K, Rask-Madsen J. Effects of topical 5-aminosalicylic acid and prednisolone on prostaglandin $\mathrm{E}_{2}$ and lukotriene $\mathrm{B}_{4}$ levels determined on prostaglandin $\mathrm{E}_{2}$ and lukotriene $\mathrm{B}_{4}$ levels determined
by equilibrium in vivo dialysis of rectum in relapsing ulcerby equilibrium in vivo dialysis of rectum in relapsin

4 Peskar BM, Dreyling KW, Peskar BA, May B, Goebell H Enhanced formation of sulfidopeptid-leukotrienes in ulcerative colitis and Crohn's disease: inhibition by sulfasalazine and 5-aminosalicylic acid. Agents Actions 1986; 18: 381-3.

5 Vilaseca J, Salas A, Guarner F, Rodriguez R, Malagelada JR. Participation of thromboxane and other eicosanoid synthesis in the course of experimental inflammatory colitis. Gastroenterology 1990; 98: 269-77.

6 Wallace JL, MacNaughton WK, Morris GP, Beck PL. Inhibition of leukotriene synthesis markedly accelerates healing in rat model of inflammatory bowel disease. Gastroenterology 1989; 98: 29-36.

7 Rachmilewitz R, Simon PL, Schwartz LW, Griswold DE Fondacaro JD, Wasserman MA. Inflammatory mediators of experimental colitis in rats. Gastroenterology 1989; 97 326-37.

8 Zipser RD, Pinzani M, Nast CC. Effects of sulfasalazine and the leukotriene inhibitor L-651,392 in rabbit colitis: evidence that $\mathrm{LTB}_{4}$ production contributes to inflammation. Gastroenterology 1987; 92: 1711 .

9 Allgayer H, Stenson WF. Role of lipoxygenase pathway products in an animal model of colitis: effects of pretreatment with 5-lipoxygenase inhibitors. Gastroenterology 1988; 94; A6.

10 Wallace $\mathrm{J}$, Keenan CM. An orally active inhibitor of leukotriene synthesis accelerates healing in a rat model of leukotriene synthesis accelerates healing in
colitis. Am f Physiol 1990; 258: G527-34.

11 Wallace IL, Keenan CM, Gale D, Shoupe TC Exacerbation of experimental colitis by nonsteroidal antiinflammatory drugs is not related to elevated leukotrien $\mathrm{B}_{4}$ synthesis. Gastroenterology 1992; 102: 18-27.

12 Laursen LS, Naesdal J, Bukhave K, Lauritsen K, RaskMadsen J. Selective 5-lipoxygenase inhibition in ulcerative colitis. Lancet 1990; 335: 683-5.

13 Peppercorn M, Das K, Elson C, Geraci K, Robinson M Rubin A, Salzberg B, Wruble L, Dube L, Rountree L, Broutman L. Zileuton, a 5-lipoxygenase inhibitor, in the treatment of active ulcerative colitis: a double-blind, placebo controlled trial. Gastroenterology 1994: A751.

14 Hawkey C, Gassull MA, Lauritsen K, Martin F, O'Morain C, Rask-Madsen J, Wright J, Dube L, Rountree L inhibitor, in the maintenance of remission in patients with ulcerative colitis. Gastroenterology 1994; 106: A697.

15 Morris GP, Beck PL, Herridge MS, Depew WT, Szewczuk MR, Wallace JL. Hapten-induced model of chronic inflammation and ulceration in the rat colon. Gastroenterology 1989; 96: 795-803.

16 Vilaseca J, Salas A, Guarner F, Rodriguez R, Martínez M Malagelada JR. Dietary fish oil reduces progression of chronic inflammatory lesions in a rat model of granulomatous colitis. Gut 1990; 31: 539-44.

17 Powell WS. Rapid extraction of oxygenated metabolites of arachidonic acid from biological samples. Prostaglandins 1980; 20: 947-57.

18 Ramis I, Roselló-Catafau J, Artigot M, Bulbena O Simultaneous reversed-phase extraction of lipoxygenase cyclooxygenase metabolites of arachidonic acid in nasal secretions; methodological aspects. F Chromatogr 1990; 532: $217-25$

19 Ramis I, Roselló-Catafau J, Gómez G, Zabay JM, Fernández-Cruz E, Gelpí E. Cyclooxygenase and lipoxygenase arachidonic acid metabolism by monocytes from human immune deficiency virus-infected drug users. f Chromatogr 1991; 557: 507-13.

20 Gelpí E, Ramis I, Hotter G, Bioque G, Bulbena O, Roselló J. Modern high-performance liquid chromatographicradioimmunoassay strategies for the study of eicosanoids in biological samples. $\mathcal{f}$ Chromatogr 1989; 492: 223-50.

21 Stenson WF. Animal models of colitis. Current Opinion in Gastroenterology 1995; 11: 310-5.

22 Sharon P, Stenson WF. Metabolism of arachidonic acid in acetic acid colitis in rats. Gastroenterology 1985; 88: 55-63.

23 LeDuc LE, Su KC, Guth E, Reedy T, Guth PH. Effects of cyclooxygenase and lipoxygenase inhibition on eicosanoids and healing of acetic acid colitis in rats. Dig Dis Sci 1993; 38: 289-94.

24 Sharon P, Ligumsky M, Rachmilewitz D, Zor U. Role of prostaglandins in ulcerative colitis. Enhanced production during active disease and inhibition by sulfasalazine. Gastroenterology 1978; 75: 638-40.

25 Rampton DS, Sladen GE, Youlten LY. Rectal mucosal prostaglandin $E_{2}$ release and its relation to disease activity, electrical potential difference and treatment in ulcerative colitis. Gut 1981; 21: 417-25.

26 Lauritsen K, Hansen J, Bytzer P, Bukhave K, Rask-Madsen $\mathrm{J}$. Effect of sulfasalazine and disodium azodisalicylate on colonic $\mathrm{PGE}_{2}$ concentration determined by equilibrium in vivo dialysis of faeces in patients with ulcerative colitis and healthy controls. Gut 1984; $25: 1271-8$.

27 Gould SR. Assay of prostaglandin-like substances and their measurement in ulcerative colitis. Prostaglandins 1976; 11: 489-97.

28 Gould SR, Brash AR, Conolly ME, Lennard-Jones JE. Studies of prostaglandins and sulfasalazine in ulcerative colitis. Prostaglandins Med 1981; 6: 165-82.

29 Kauffmann HJ, Taubin HL. Nonsteroidal anti-inflammatory drugs activate quiescent inflammatory bowel disease. Ann Intern Med 1987; 107: 513-6.

30 Gibson GR, Whitacre EB, Ricotti CA. Colitis induced by nonsteroidal anti-inflammatory drugs. Arch Intern Med 1992; 152: 625-33.

31 Allgayer H, Deschryver K, Stenson WF. Treatment with $16,16^{\prime}$-dimethyl prostaglandin $E_{2}$ before and after induction os colitis with trinitrobenzenosulfonic acid in rats decreases inflammation. Gastroenterology 1989; 96: 1290-300.

32 Wallace JL, Whittle BJR, Boughton-Smith NK Prostaglandin protection of the rat colonic mucosa from damage induced by ethanol. Dig Dis Sci 1985; 30: 866-76.

33 Yamada T, Specian RD, Granger DN, Gaginella TS, Grisham MB. Misoprostol attenuates acetic acid-induced increases in mucosal permeability and inflammation: role of blood flow. Am $\mathcal{F}$ Physiol 1991; 261: G332-9.

34 Zijlstra FJ, Srivastava ED, Rhodes M, van Dijk APM, Fogg F, Samson HJ, Copeman M, Russell MAH, Feyerabend F, Samson HJ, Copeman M, Russell MAH, Feyerabend C, Williams GT, Pullan RD, Thomas GAO, Van
Blankenstein M, Wilson JHP, Allen A, Rhodes J. Effect of nicotine on rectal mucus and mucosal eicosanoids. Gut 1994; 35: 247-51.

35 Gryglewski RJ, Szczeklik A, Wandzilak M. The effect of six prostaglandins, prostacyclin and iloprost on generation of superoxide anions by human polymorphonuclear leucocytes stimulated by zymosan or formyl-methionyl-leucylphenylalanine. Biochem Pharmacol 1987; 36: 4209-12

36 Betz M, Fox BS. Prostaglandin $\mathrm{E}_{2}$ inhibits production of Th1 lymphokines but not of Th2 lymphokines. 7 Immunol 1991; 146: 108-13.

37 Goto T, Herberman RB, Maluish A, Strong DM. Cyclic AMP as a mediator of prostaglandin E-induced suppression of human 130 : $1350-5$.

38 Kunkel SL, Chensue SW, Phan SH. Prostaglandins as endogenous mediators of interleukin 1 production. $\mathcal{f}$ Immunol 1986; 136: 186-8.

39 Beno DWA, Espinal R, Edelstein BM, Davis BH Administration of prostaglandin-E1 analog reduces rat hepatic and Ito cell collagen gene expression and collagen accumulation after bile duct ligation injury. Hepatology 1993; 17: 707-14.

40 Zahner G, Disser M, Thaiss F, Wolf G, Schoeppe W, Stah RAK. The effect of prostaglandin $E_{2}$ on mRNA expression and secretion of collagens I, III, and IV and fibronectine in cultured rat mesangial cells. $\mathrm{f} \mathrm{Am}$ Soc Nephrol 1994; 4: 1778-85.

41 Surawicz CM, Belic C. Rectal biopsy helps to distinguish acute self-limited colitis from idiopathic inflammatory bowel disease. Gastroenterology 1984; 86: 104-13. 